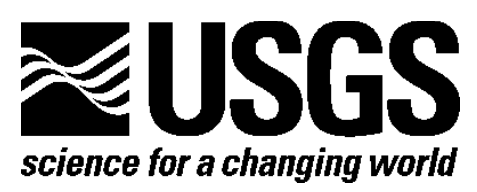

Prepared in cooperation with the Federal Emergency Management Agency, the National Geospatial-Intelligence Agency, and the Natural Resources Conservation Service

\title{
National Requirements for Enhanced Elevation Data
}

By Gregory I. Snyder, Larry J. Sugarbaker, Allyson L. Jason, and David F. Maune

Open-File Report 2013-1237

U.S. Department of the Interior

U.S. Geological Survey 


\section{U.S. Department of the Interior \\ SALLY JEWELL, Secretary}

\section{U.S. Geological Survey \\ Suzette M. Kimball, Acting Director}

\section{U.S. Geological Survey, Reston, Virginia: 2013}

For more information on the USGS-the Federal source for science about the Earth, its natural and living resources, natural hazards, and the environment-visit http://www.usgs.gov or call 1-888-ASK-USGS (1-888-275-8747)

For an overview of USGS information products, including maps, imagery, and publications, visit http://www.usgs.gov/pubprod

To order this and other USGS information products, visit http://store.usgs.gov

Any use of trade, firm, or product names is for descriptive purposes only and does not imply endorsement by the U.S. Government.

Although this information product, for the most part, is in the public domain, it also may contain copyrighted materials as noted in the text. Permission to reproduce copyrighted items must be secured from the copyright owner.

This draft manuscript is distributed solely for purposes of scientific peer review. Its content is deliberative and predecisional, so it must not be disclosed or released by reviewers. Because the manuscript has not yet been approved for publication by the U.S. Geological Survey, it does not represent any official USGS finding or policy.

Suggested citation:

Snyder, G.I., Sugarbaker, L.J., Jason, A.L., and Maune, D.F., 2012, National requirements for enhanced elevation data: U.S. Geological Survey Open-File Report 2013-1237, 371 p., http://pubs.usgs.gov/of/2013/1237/.

ISSN 2331-1258 (online) 


\section{Acknowledgements}

The authors would like to acknowledge the efforts of all organizations who participated in the online survey and subsequent workshops. Special thanks go to the Federal points of contact that coordinated their agency input as well as the U.S. Geological Survey Geospatial Liaisons who managed the collection of State, local, and tribal enhanced elevation data requirements. Funding support from the U.S. Geological Survey, the National Geospatial-Intelligence Agency, the Federal Emergency Management Agency, and the Natural Resources Conservation Service was critical to the completion of the study. 


\section{Contents}

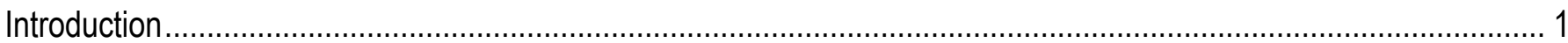

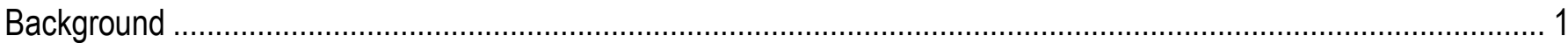

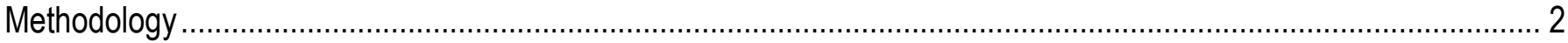

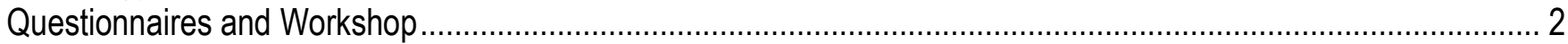

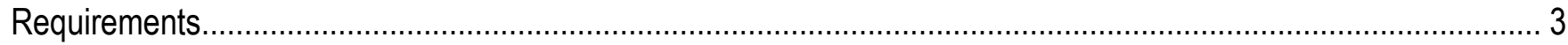

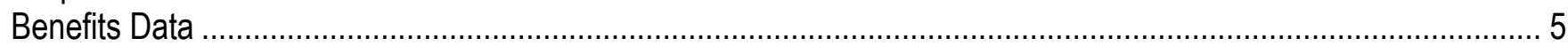

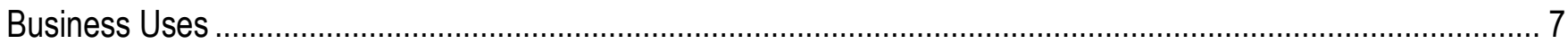

Summary

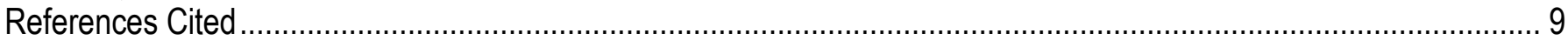

Appendix 1. Federal Government Requirements and Benefits Data ..............................................................12

Appendix 2. State, Territory, Local, and Tribal Government Requirements and Benefits Data ...............................156

Appendix 3. Nongovernmental Requirements and Benefits Data ………….....................................................360

\section{Figures}

1. Chart showing the number of requirements for each quality level. ....................................................... 5

2. Chart showing the cumulative benefits, in million dollars, for each quality level. .......................................... 6

\section{Tables}

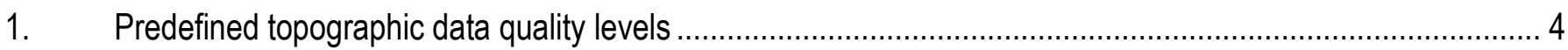

$2 \quad$ Aggregated benefits from enhanced elevation data................................................................................ 7

\section{Conversion Factors}

\begin{tabular}{llll}
\hline & Bultiply & & To obtain \\
\hline & Length & \\
\hline centimeter $(\mathrm{cm})$ & 0.3937 & inch (in.) & \\
meter $(\mathrm{m})$ & 3.281 & foot (ft) & \\
meter $(\mathrm{m})$ & 1.094 & yard (yd) & \\
\hline & Area & \\
\hline square meter $\left(\mathrm{m}^{2}\right)$ & 0.0002471 & acre & \\
\hline
\end{tabular}




\title{
National Requirements for Enhanced Elevation Data
}

\author{
By Gregory I. Snyder, Larry J. Sugarbaker, Allyson L. Jason, and David L. Maune
}

\section{Introduction}

This report presents the results of surveys, structured interviews, and workshops conducted to identify key national requirements for improved elevation data for the United States and its territories, including coastlines. Organizations also identified and reported the expected economic benefits that would be realized if their requirements for improved elevation were met (appendixes 1-3). This report describes the data collection methodology and summarizes the findings. Participating organizations included 34 Federal agencies, 50 States and two territories, and a sampling of local governments, tribes, and nongovernmental orgnizations. The nongovernmental organizations included The Nature Conservancy and a sampling of private sector businesses. These data were collected as part of the National Enhanced Elevation Assessment (NEEA), a study to identify program alternatives for better meeting the Nation's elevation data needs. NEEA tasks include the collection of national elevation requirements; analysis of the benefits and costs of meeting these requirements; assessment of emerging elevation technologies, lifecycle data management needs, and costs for managing and distributing a national-scale dataset and derived products; and candidate national elevation program alternatives that balance costs and benefits in meeting the Nation's elevation requirements. The NEEA is being sponsored by the National Digital Elevation Program (NDEP), a government coordination body with the U.S. Geological Survey (USGS) as managing partner that includes the National Geospatial-Intelligence Agency (NGA), the Federal Emergency Management Agency (FEMA), the Natural Resources Conservation Service (NRCS), the U.S. Army Corps of Engineers (USACE), and the National Oceanic and Atmospheric Administration (NOAA), among the more than a dozen agencies and organizations. The term enhanced elevation data as used in this report refers broadly to three-dimensional measurements of land or submerged topography, built features, vegetation structure, and other landscape detail.

\section{Background}

Light detection and ranging (lidar) has evolved as an essential remote sensing technology needed to support high-value applications, such as flood risk management, water supply and quality, infrastructure and construction management, natural resources conservation, geologic resource assessment, and hazard mitigation. Lidar is one of two primary technologies used in the United States to support mapping of elevation and other Earth surface characteristics. Interferometric synthetic aperture radar (IFSAR), while generally lower in absolute accuracy and resolution, has the advantage of being able to penetrate cloud cover and presents a lower initial data acquisition cost due to higher altitude and faster flight collection parameters.

Federal agencies including the USGS, the NRCS, NOAA, the NGA, and the USACE are making significant investments in lidar data collection programs. In addition, more than 10 States either have 
Federal agencies including the USGS, the NRCS, NOAA, the NGA, and the USACE are making significant investments in lidar data collection programs. In addition, more than 10 States either have started, have completed, or are actively planning statewide lidar programs. Elevation data collection projects are usually cooperative efforts between many organizations over specific geographic areas where funding and requirements coincide. Data consistency often varies across projects, a condition that may hinder or complicate analysis over large geographic areas or project boundaries. To date, limited resources at all levels of government leave much of the United States without adequate or consistent elevation data. In addition, the current cooperative model has no provisions for the lifecycle data management costs to include a publically accessible data repository.

Although the USGS has been incorporating high-resolution elevation data derived from lidar into the National Elevation Dataset (NED) since 2003, about 70 percent of NED source data are more than 30 years old and not sufficiently accurate to meet user requirements for many applications.

The lack of sufficient data has been noted by NDEP agencies, the broader user community, and in some nationally recognized science reports. For example, two reports from the National Research Council (NRC; 2007, 2009) concluded that accurate topographic data are the most important factor in flood risk mapping and the determination of water surface elevations, base flood elevations, and the extent of flooding; the United States needs nationwide lidar with applications well beyond FEMA's requirements for floodplain mapping; and FEMA should increase its collaboration with other Federal, State, and local government agencies to acquire high-resolution, high-accuracy topographic and bathymetric data throughout the Nation. With the increasingly widespread acceptance of lidar technology, discussions within the NDEP and the lidar user community have turned toward improved coordination and planning programs of a national scope. The NEAA study was undertaken to identify more efficient and robust approaches for meeting priority national elevation requirements.

\section{Methodology}

\section{Questionnaires and Workshop}

Points of contact (POCs) were established within Federal and State agencies to selectively identify participants that were best able to represent their organization's requirements. The Federal and State requirements and benefits data were collected through online questionnaires and subsequent workshops. Respondents included content experts and managers from participating organizations. Federal POCs are listed at the beginning of each agency entry in appendix 1. USGS geospatial liaisons (U.S. Geological Survey, undated) worked with their State and local government counterparts to collect the information reported in appendix 2.

The goal of the questionnaire was to capture what organizations deemed to be their requirements for elevation data, including elevation data quality, update frequency, and geographic area of interest, as well as the expected benefits to be realized by enhanced elevation data. Each program activity (functional activity) was described by respondents in their own words and linked to one of 27 predefined business uses for the purposes of aggregation and analysis. A total of 358 questionnaire responses were received from Federal respondents, and 363 responses were received from State and local government representatives, including tribes. The questionnaire was conducted online using Survey Monkey ${ }^{\mathrm{TM}}$ and linked to a "Frequently Asked Questions” page where respondents could turn for additional information about technical terms or concepts used in the questionnaire. To identify "true" data needs versus “nice-to-have” data needs, agencies were asked to provide only mission-critical 
requirements, defined as "indispensable for mission accomplishment and/or essential for effective/efficient operations in accomplishing the core mission of the organization.”

Workshops were held within the participating organizations, as a means for checking and completing data submitted through the online questionnaires. In many cases, workshop discussions resulted in the data being modified, updated, or consolidated. The workshop attendees included questionnaire respondents as well as other content specialists and managers within the various organizations. After the workshop, agencies received their revised data in a report form and certified it as final. Data collected from local (county, city, and regional) and tribal governments were also collected by online questionnaires, but not reviewed and validated in workshops, and are included in this report as received. The data received from nongovernmental organizations were collected in interviews.

\section{Requirements}

Within the questionnaire and workshop process, participants were asked to define their requirements and expected benefits related to their activities in terms of data quality (elevation data density, accuracy) data repeat cycle, benefits, and geographic areas of interest. Data quality choices included five quality levels (QLs). These QLs relate to data typically produced by candidate technologies, which included lidar, photogrammetry (using existing aerial imagery), and airborne IFSAR. The technical specifications of the five topographic QLs are listed in table 1; the sources and uses of the QLs are explained as follows:

- QL1 - lidar data are typically acquired for demanding requirements that include the need for high lidar point data density and accuracy. For example, in heavily forested areas, QL1 data may be required to fully characterize vegetation structure or to assure that a sufficient number of lidar pulses will penetrate the canopy to provide detailed mapping of the underlying topography.

Geologic fault detection and identification of previous landslides in heavily vegetated areas may require QL1 data. Other applications where high accuracy and point density may be critical are airport aviation safety and infrastructure citing and management.

- QL2-lidar data are needed for applications that require high accuracy but less demanding point densities. For example, QL2 data may be applicable for coastal zone management, conservation planning, wetlands mapping, soil mapping, and sea-level rise assessment.

- QL3-Most lidar data acquired during the past decade have been acquired by Federal and State agencies in the QL3 range to meet a more basic set of application requirements, such as floodplain mapping and general topographic mapping.

- QL4-Elevation data can be produced from stereo-aerial imagery during the production of digital orthophotos. These images and some ancillary data can be reused to photogrammetrically produce elevation data. For the purposes of this study, QL4 is defined as the quality of elevation data that could be produced by photogrammetrically deriving elevation data from existing imagery collected by the U.S. Department of Agriculture’s National Agricultural Imagery Program (NAIP). There were very few requirements identified for QL4.

- QL5-Although elevation data and imagery derived from IFSAR are generally the least accurate of the five QLs, IFSAR provides a significant advantage in Alaska where the technology can operate in most all atmospheric and weather conditions. 
Table 1. Predefined topographic data quality levels. [IFSAR, interferometric synthetic aperture radar; lidar, light detection and ranging]

\begin{tabular}{|c|c|c|c|c|c|c|}
\hline \multirow[b]{2}{*}{$\begin{array}{l}\text { Elevation } \\
\text { QLs }^{1}\end{array}$} & \multicolumn{3}{|c|}{ Horizontal resolution terms } & \multicolumn{2}{|c|}{ Vertical accuracy terms } & \multirow[b]{2}{*}{ Principal source ${ }^{7}$} \\
\hline & $\begin{array}{c}\text { Nominal point } \\
\text { density }{ }^{2} \text {, in } \\
\text { pts } / \mathrm{m}^{2}\end{array}$ & $\begin{array}{l}\text { Nominal pulse } \\
\text { spacing }^{3} \text {, in } \\
\text { meters }\end{array}$ & $\begin{array}{l}\text { DEM post } \\
\text { spacing }^{4} \text {, in } \\
\text { meters }\end{array}$ & $\begin{array}{l}\text { Vertical RMSE }{ }^{5} \text {, in } \\
\text { centimeters }\end{array}$ & $\begin{array}{l}\text { Equivalent contour } \\
\text { accuracy }^{6} \text {, in feet }\end{array}$ & \\
\hline QL2 & 2 & 0.7 & $\sim 1$ & 9.25 & 1 & Lidar. \\
\hline QL3 & $1-0.25$ & $1-2$ & $\sim 3$ & $\leq 18.5$ & 2 & Lidar. \\
\hline QL4 & 0.04 & 5 & $\sim 10$ & $46.3-139$ & $5-15$ & Aerial imagery. \\
\hline
\end{tabular}

${ }^{1} \mathrm{QL}$, quality level.

${ }^{2}$ Point density estimates the number of first-return lidar pulses per square meter; it is the inverse of nominal pulse spacing (NPS) and is typically used when the NPS is equal to or less than 1 meter.

${ }^{3} \mathrm{NPS}$, an alternative measure of the density of a lidar dataset, is the typical or average lateral distance between irregularlyspaced points in a lidar dataset, most simply calculated and expressed as the square root of the average area per elevation point.

${ }^{4}$ Digital elevation model (DEM) post spacing refers to the regularly spaced distance between centroids of individual pixels in a raster DEM.

${ }^{5}$ Vertical root mean square error (RMSE), the square root of the mean of squared elevation errors for a sample, is a statistical term used to estimate elevation errors at different confidence levels when elevation errors approximate a normal error distribution. For example, vertical accuracy at the 90 percent confidence level is calculated as RMSE $\times 1.6449$, and vertical accuracy at the 95 percent confidence level is calculated as RMSE $\times 1.9600$.

${ }^{6}$ Equivalent contour accuracy refers to the contour interval that can be legitimately derived from a set of elevation points. When errors follow a normal error distribution, the equivalent contour accuracy $=3.2898 \times$ RMSEz. Typically, 90 percent of elevation errors in the dataset will be less than or equal to one-half the equivalent contour accuracy.

${ }^{7}$ Principal source refers to the technology that is typically used to produce the quality level described.

General requirements for near-shore bathymetric lidar data were also collected (fig. 1). Survey participants were asked if a standard quality level, defined as data points spaced from 3 to 5 meters apart with a root mean square error of 20 centimeters, was sufficient or if higher quality data were needed. Additionally, respondents were asked if bathymetric (or topographic) lidar data collection needed to be coordinated with a particular coastal tide stage. Many of the bathymetric requirements submitted were located in areas where bathymetric lidar is not feasible due to turbid waters. These requirements could only be successfully met with sonar or manual depth measurement methods beyond the scope of this study. Bathymetric lidar requirements from the USGS, NOAA, and USACE did fall in areas where bathymetric lidar is operable. 


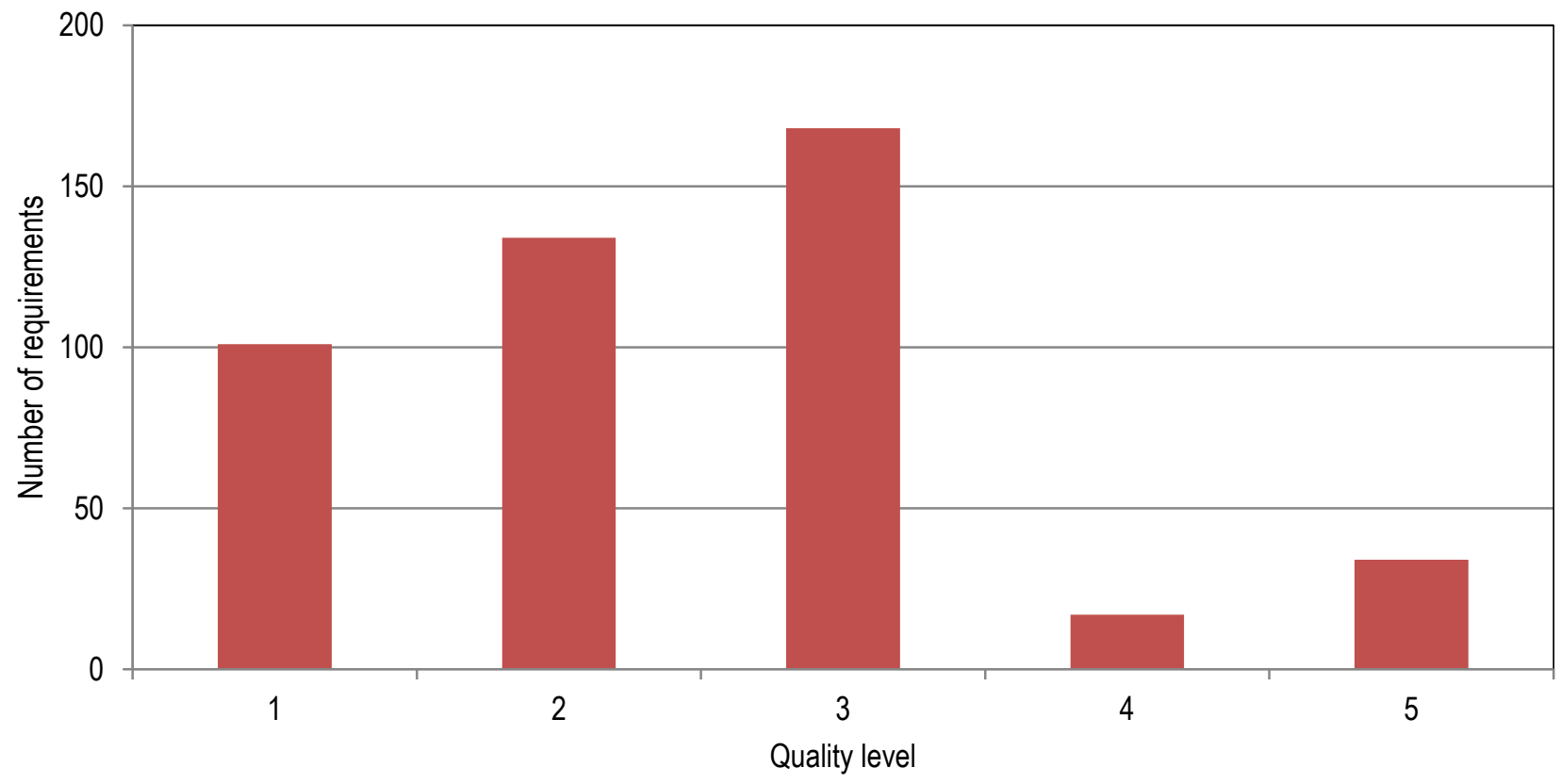

Figure 1. Chart showing the number of requirements for each quality level.

Survey participants were asked to further characterize their requirements by the desired frequency of update (annually, 4-5 years, 8-10 years, greater than 10 years, and as "event driven" requirements that could not be fully met by a cyclical program). A number of requirements were mischaracterized as event driven when in fact they were associated with ongoing programs that address event driven applications. For example, an ongoing floodplain mapping activity is an ongoing program that addresses flood events, not a periodic effort invoked by a flood event. Because the benefits for event driven activities were only recorded at 50 percent and some of the activities were mischaracterized as event driven, benefits for some activities are lower than they would otherwise be. The reason that event driven programs only received 50 percent of expected benefits is because a cyclical data collection program would be expected to satisfy pre-event but not post-event requirements.

\section{Benefits Data}

Benefits were captured in several categories, including operational benefits, customer service improvements, and other societal or strategic benefits (fig. 2). Operational benefits refer to benefits that would accrue within an organization, such as increased productivity or a reduction of costs. Customer service benefits are those realized by an organization's customers through improved products and services. Societal or strategic benefits are difficult to monetize, such as some ecosystem services or improvements in the perceived relevance of an organization. Each functional activity had requirements and benefits linked to spatial files that define specific geographic areas for which the requirements and benefits pertain. 


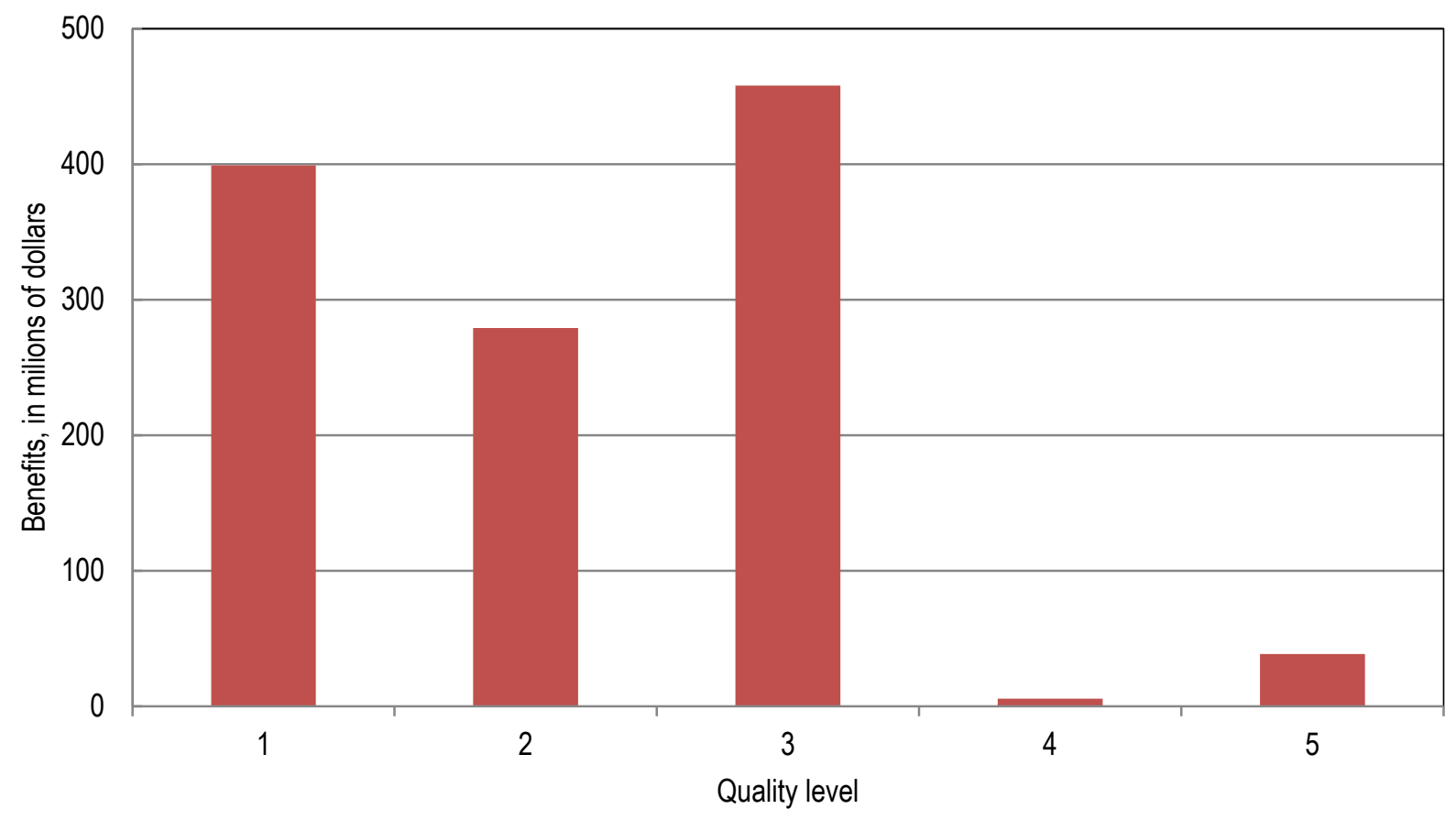

Figure 2. Chart showing the cumulative benefits, in million dollars, for each quality level.

The total benefits documented in this assessment were calculated as "conservative" and "potential." Conservative benefits are believed to be significantly lower than they might actually be for several reasons:

- this assessment did not identify and capture all applications for elevation data

- of the organizations that did document applications, approximately half were unable to quantitatively estimate expected dollar benefits, even though most of these same organizations reported that they expected moderate or major benefits

- benefits were sometimes provided as a range of dollars, and in such cases the number representing the low end of the range was used

- benefits do not include county, regional, city, and tribal governments because the sample pools for these organizations were too small to support national projections, because shapefiles were not captured, and because these organizations did not participate in the State interviews and workshops

Another approach was used to estimate "potential" benefits, computed as follows:

- where a dollar benefit range was provided, the high number was used

- for activities that expected large benefits but were not able to quantify the benefits, benefits were generally estimated to be 0.1 percent of the activities budget

- there was some limited extrapolation of benefits from local governments to local governments nationally (from small samples)

- the numbers included estimated benefits from selected emerging applications.

Even the potential benefits are believed to be considerably underestimated and could be one or more order of magnitudes greater if the study had included the expected benefits of every county, regional, city, and tribal government and other industries nationwide. Table 2 presents the tally of conservative and potential benefits as aggregated under the 27 business uses developed for this study. 
Table 2. Aggregated benefits from enhanced elevation data.

[Data are presented sorted by conservative benefits. —, reported benefits less than 1 million (M)]

\begin{tabular}{|c|c|c|}
\hline \multirow{2}{*}{ Business use } & \multicolumn{2}{|c|}{ Annual benefits from enhanced elevation data, in million dollars } \\
\hline & Conservative benefits & Potential benefits \\
\hline Flood risk management & 295 & 502 \\
\hline Infrastructure and construction management & 206 & 942 \\
\hline Natural resources conservation & 159 & 335 \\
\hline Agriculture and precision farming & 122 & 2,011 \\
\hline Water supply and quality & 85 & 156 \\
\hline Wildfire management, planning, and response & 76 & 159 \\
\hline Geologic resource assessment and hazard mitigation & 52 & 1,067 \\
\hline Forest resources management & 44 & 62 \\
\hline River and stream resource management & 38 & 87 \\
\hline Aviation navigation and safety & 35 & 56 \\
\hline Coastal zone management & 24 & 42 \\
\hline Renewable energy resources & 10 & 100 \\
\hline Oil and gas resources & 10 & 100 \\
\hline Homeland security, law enforcement, disaster response & 10 & 126 \\
\hline Sea level rise and subsidence & 6 & 22 \\
\hline Urban and regional planning & 4 & 69 \\
\hline Resource mining & 2 & 5 \\
\hline Wildlife and habitat management & 2 & 4 \\
\hline Education $\mathrm{K}-12$ and beyond & - & 2 \\
\hline Land navigation and safety & - & 7,125 \\
\hline Telecommunications & - & 2 \\
\hline Recreation & - & - \\
\hline Cultural resources preservation and management & - & 7 \\
\hline Health and human services & - & 1 \\
\hline Marine navigation and safety & - & - \\
\hline Real estate, banking, mortgage, insurance & - & - \\
\hline Rangeland management & - & - \\
\hline Total estimated annual dollar financial benefits & 1,180 & 12,981 \\
\hline
\end{tabular}

In addition to the underreporting of benefits, there was variability (actual or apparent) particularly in the benefits reported among States. For example, the flood risk management benefits reported by North Carolina seem high compared to other coastal States. However, flood benefits were either not reported or significantly underestimated by other coastal or interior States where significant flood-related benefits would have been expected. In addition, some States reported functional activities that would also have been expected to be reported by other States, but were not mentioned by other States. One likely reason is that States were asked to identify their "top" five or six functional activities, and these priorities varied from State to State. Overall, although a consistent and structured process was used for collecting, reviewing, and finalizing the requirements and benefits across organizations, reporting variability resulted in significantly underestimated benefits.

\section{Business Uses}

For the purposes of aggregating and analyzing the data, respondents were asked to link their functional activities to one of 27 predefined business uses. The following is a list of the standard business uses along with some example activities that fell within them.

1. Natural resources conservation. Example activities include conservation engineering, soils mapping, wetlands mapping and characterization, and assessment of biological carbon stocks.

2. Water supply and quality. Example activities include management of water and power delivery, water resource planning and management, water forecasting, water quality investigations, and pollution risk mitigation. 
3. River and stream resource management. Example activities include monitoring river flows and fish habitat, stream restoration, storm water management, and inland waterway navigation.

4. Coastal zone management. Example activities include coastal mapping and modeling, coastal hazards mitigation, tsunami modeling, and land use and environmental planning.

5. Forest resources management. Example activities include forest inventories, forest resource management, sustainable timberlands, forest species distribution modeling, and forest conservation.

6. Rangeland management. Example activities include preservation and management of rangeland, rangeland stewardship, and rangeland mapping and characterization.

7. Wildlife and habitat management. Example activities include conservation planning for wildlife refuges, conservation of critical habitats, and management of diverse migratory bird habitats.

8. Agriculture and precision farming. Example activities include optimizing yields and reducing harmful runoff by site-specific application of fertilizer and pesticides and optimizing farm practices.

9. Geologic resource assessment and hazard mitigation. An example activity includes detailed geologic mapping to understand and mitigate landslide, seismic, and volcano risks to infrastructure and populations.

10. Resource mining. Example activities include regulation and permitting of coal mining activities, reclamation of coal mining areas, and monitoring of postmining conditions.

11. Renewable energy resources. Example activities include assessment of solar and wind energy potential and planning and siting wind farms and solar facilities.

12. Oil and gas resources. Example activities include pipeline and road route selection, facility siting to mitigate seismic hazards, and regulatory compliance.

13. Cultural resources preservation and management. Example activities include cultural resource identification, protection, and management (for example, archeological sites and historic structures).

14. Flood risk management. Example activities include flood risk analysis and flood plain mapping, emergency management, levee safety, flood forecasts, and hydrologic and hydraulic modeling.

15. Sea-level rise and subsidence. Example activities include mapping and modeling and forecasting the effects of sea-level rise and population and economic vulnerability assessments.

16. Wildfire management, planning and response. Example activities include understanding, modeling, and predicting fire behavior, protection of ecosystems, and fire-fuel estimations.

17. Homeland security, law enforcement, and disaster response. Example activities include infrastructure and border protection, coastal search and rescue, population dynamics, and viewshed modeling.

18. Land navigation and safety. Example activities include railroad grade safety and asset management, in-car navigation products and services, and future automotive innovations to increase fuel efficiency.

19. Marine navigation and safety. Example activities include coastal and bathymetric mapping, identification of hazards to navigation, and sediment management at coastal navigation projects. 
20. Aviation navigation and safety. Example activities include development of airport terminal instrument procedures and visual and instrument flight rule charts, and identification of obstacles near airfields.

21. Infrastructure and construction management. Example activities include military base and facility feasibility and planning, design and placement of infrastructure (for example, roads and bridges, power generating facilities), and transmission-line vegetation management.

22. Urban and regional planning. Example activities include land development and zoning, municipal mapping of building footprints and impervious surfaces, and parks and transportation planning.

23. Health and human services. Example activities include health emergency response, habitat modeling and disease prevention, public health and safety, and prevention of waterborne diseases.

24. Real estate, banking, mortgage, and insurance. Example activities include assessment of risk for natural hazards to inform insurance policy rates and the determination of mandatory insurance.

25. Education $K-12$ and beyond. Example activities include understanding and continental-scale climate change impacts, land cover monitoring, and development of military training simulators.

26. Recreation. Example activities include development of recreational facilities, such as ski areas, golf courses, trails, and fishing areas, and location-based products and services for bikers, climbers, and other recreational uses.

27. Telecommunications. Example activities include broadband mapping for wireless communications, frequency interference analysis, and municipal placement of antennas and cameras observations.

\section{Summary}

Significant benefits are expected to accrue from the availability of enhanced elevation data (table 1). The largest benefit relates to flood hazards. Topographic elevation is the primary determinant that controls the location, direction, speed, and destructive force of water flow. Improved elevation data supports the development of more accurate flood maps and enhances flood risk mitigation strategies. Additionally, there are emerging business applications for enhanced elevation data in nontraditional communities of use that have the potential for extraordinary effect. For example, agriculture and precision farming applications have significant potential benefits for increased agriculture yields, tailored application of seed and fertilizer, and reduced pollution from farm-field runoff. Land navigation and safety applications would save fuel and lower costs for ground transportation and the transport of goods. There are likely a host of other private sector advantages to industries that were not included in appendix 3. It is also expected that complete national cover would encourage new geospatial tools and services that are not possible or supported given the current limited and disparate availability of elevation data.

\section{References Cited}

National Research Council, 2007, Elevation data for floodplain mapping: The National Academies Press, 151 p. (Accessed March 7, 2012, at www.nap.edu/openbook.php?record_id=11829\&page=151.) 
National Research Council, 2009, Mapping the zone-Improving flood map accuracy: The National Academies Press, 136 p.

U.S. Geological Survey, [undated], U.S. Geological Survey-National Geospatial Program partnerships: U.S. Geological Survey, accessed September 9, 2013, at http://liaisons.usgs.gov/geospatial/documents/TNM_Partnership_User_ContactList.pdf. 


\section{Appendix 1. Federal Government Requirements and Benefits Data}

Appendix 2. State, Territory, Local, and Tribal Government Requirements and Benefits Data

Appendix 3. Nongovernmental Requirements and Benefits Data 
ISSN 2331-1258 (online)

http://dx.doi.org/10.3133/ofr20131237 